\title{
BMJ Open Economic costs of chronic disease through lost productive life years (PLYs) among Australians aged 45-64 years from 2015 to 2030: results from a microsimulation model
}

\author{
Deborah Schofield, ${ }^{1,2,3}$ Rupendra N Shrestha, ${ }^{1}$ Michelle M Cunich, ${ }^{1}$ \\ Robert Tanton, ${ }^{4}$ Lennert Veerman, ${ }^{5}$ Simon J Kelly, ${ }^{4}$ Megan E Passey ${ }^{6}$
}

To cite: Schofield D, Shrestha RN, Cunich MM, et al. Economic costs of chronic disease through lost productive life years (PLYs) among Australians aged 4564 years from 2015 to 2030 : results from a microsimulation model. BMJ Open 2016;6:e011151. doi:10.1136/bmjopen-2016011151

- Prepublication history for this paper is available online. To view these files please visit the journal online (http://dx.doi.org/10.1136/ bmjopen-2016-011151).

Received 15 January 2016 Revised 20 July 2016 Accepted 31 August 2016

CrossMark

For numbered affiliations see end of article.

Correspondence to Dr Michelle M Cunich; michelle.cunich@sydney. edu.au

\section{ABSTRACT}

Objectives: To project the number of older workers with lost productive life years (PLYs) due to chronic disease and resultant lost income; and lost taxes and increased welfare payments from 2015 to 2030.

Design, setting and participants: Using a microsimulation model, Health\&WealthMOD2030, the costs of chronic disease in Australians aged 45-64 were projected to 2030 . The model integrates household survey data from the Australian Bureau of Statistics Surveys of Disability, Ageing and Carers (SDACs) 2003 and 2009, output from long-standing microsimulation models (STINMOD (Static Incomes Model) and APPSIM (Australian Population and Policy Simulation Model)) used by various government departments, population and labour force growth data from Treasury, and disease trends data from the Australian Burden of Disease and Injury Study (2003). Respondents aged 45-64 years in the SDACs 2003 and 2009 formed the base population.

Main outcome measures: Lost PLYs due to chronic disease; resultant lost income, lost taxes and increased welfare payments in 2015, 2020, 2025 and 2030.

Results: We projected 380000 (6.4\%) people aged 45-64 years with lost PLYs in 2015, increasing to $462000(6.5 \%)$ in 2030—a 22\% increase in absolute numbers. Those with lost PLYs experience the largest reduction in income than any other group in each year compared to those employed full time without a chronic disease, and this income gap widens over time. The total economic loss due to lost PLYS consisted of lost income modelled at \$A12.6 billion in 2015 , increasing to $\$ A 20.5$ billion in 2030 - $62.7 \%$ increase. Additional costs to the government consisted of increased welfare payments at \$A6.2 billion in 2015, increasing to $\$ A 7.3$ billion in 2030 - $17.7 \%$ increase; and a loss of $\$ A 3.1$ billion in taxes in 2015, increasing to $\$ A 4.7$ billion in 2030 - a growth of $51.6 \%$.

Conclusions: There is a need for greater investment in effective preventive health interventions which improve workers' health and work capacity.

\section{Strengths and limitations of this study}

- The first Australian study to project the economic costs of older workers exiting the labour market due to chronic disease from the perspective of individuals, government and the nation over a long-time horizon (ie, out to 2030).

- The study uses a microsimulation model on the impacts of ill health, Health\&WealthMOD2030, which integrates output from two long-standing income, tax and welfare payments microsimulation models (Static Incomes Model and Australian Population and Policy Simulation Model) and reliable labour force and disease trends data.

- Study findings are based on Surveys of Disability, Ageing and Carer respondents' selfreported labour force status and chronic disease.

- This study provides novel insights into the interdependency of chronic disease, labour force participation and economic outcomes, with potential implications for clinical care, health policy (and setting priorities) by supporting preventive health interventions which improve the health outcomes and capacity to work of people with chronic disease and subsequently have an impact on longer term costs (such as personal incomes, welfare payments, tax paid).

\section{INTRODUCTION}

A substantial increase in years lived with disability (YLDs) globally has occurred in the past 20 years. Global Burden of Disease Collaborators (2015) estimated YLDs for 301 acute and chronic diseases and injuries and 2337 sequelae using DisMod-MR and reported 537.6 million YLDs from all causes globally in 1990 , increasing to 764.8 million in 2013 due to population growth and ageing. ${ }^{1}$ Although this study provides essential information about current and expected 
YLDs for chronic diseases, governments are concerned about the impact of chronic disease on the capacity of citizens to remain in the labour force, that is, productive life years (PLYs) lost due to chronic disease, which we define as the loss of productivity because of individuals not being able to participate in the labour force due to their chronic conditions. This is computed as the number of individuals not in the labour force because of their ill health at particular time points. These are the individuals who would be in the labour force if they did not have a chronic condition. ${ }^{2}$

The significant economic costs of chronic disease have been emphasised for OECD members. ${ }^{3}{ }^{4}$ For example, $25 \%$ of men and $21 \%$ of women aged 45 years and over reported ceasing full-time employment because of 'their own sickness, injury or disability' in Australia in 20122013..$^{5}$ Moreover, $8.5 \%$ of people aged 19-44 years reported being out of the labour force due to ill health, whereas $22.2 \%$ of people aged $45-64$ years reported being out due to ill health, thus supporting the focus of this paper on examining the impact of chronic disease on premature retirement. Most OECD countries have an ageing population, generating a number of challenges. An increase in the number of people living with chronic disease (related to ageing) places greater pressure on health systems, may add to labour shortages and increase government spending on vital services such as welfare. Cooke $^{6}$ reviews the policies used to encourage the labour force participation of older workers in the six OECD countries in the Workforce Aging in the New Economy (WANE) project. The Australian Government's priority of 'healthy ageing' is designed to encourage older people to contribute longer to the economy and, for this reason, it has implemented polices to promote deferred retirement. ${ }^{7}$

Most estimates of the economic costs of chronic disease are limited to a single condition. For example, the national cost of arthritis has been estimated for New Zealand, ${ }^{8}$ and mental illness for patients in Australia. ${ }^{9}$ However, these studies do not consider lost income, taxes and increased welfare spending as costs for governments. Even reports by the WHO and OECD, focusing on a larger number of countries, have only estimated the impact of three to five diseases (cardiovascular disease, cancer, diabetes and stroke, heart disease, chronic lung disease, depression) for either individuals who exit from paid work due to chronic disease (negative health effects) or costs measured at the national level (lost income, lost GDP). ${ }^{10}{ }^{11}$ We have previously examined the economic costs of chronic disease generally, ${ }^{2}$ and the top conditions taking older workers out of the labour force (such as back pain ${ }^{12}$ ). However, these studies have only considered a single year (2009) for estimating costs. The current study aims to project lost PLYs due to chronic disease and resultant lost income for individuals, and lost taxes and increased welfare payments for government from 2015 to 2030. This places the study among research projecting the economic costs of chronic disease a decade or more from now, but also makes an original contribution by measuring these costs from different perspectives (including budget impacts)

\section{METHODS \\ Data}

We analysed the output data sets from a microsimulation model Health\&WealthMOD2030_-Australia's first microsimulation model of the impacts of health and disability in people aged $45-64$ years covering 20 years.

The base population of Health\&WealthMOD2030 was assembled from unit-record data from the Australian Bureau of Statistics' (ABS) cross-sectional Surveys of Disability, Ageing and Carers (SDAC) 2003 and 2009. ${ }^{13} 14$ From the combined data, the records of people aged 4564 years and others in their family were extracted. For each individual in the base population, there are demographic (age, sex, family type), socioeconomic (education, income, income or other support payments), labour force (labour force participation, employment restrictions, retirement) and health variables (chronic conditions). The development of Health\&WealthMOD2030 is described in detail in Schofield $e t a .^{15}$ The main components of Health\&WealthMOD2030 and how they are linked are illustrated in figure 1.

Using a static microsimulation model, STINMOD (Static Incomes Model) ${ }^{16}$ additional economic information was imputed onto the base population (including income, welfare payments, taxes paid). STINMOD is the National Centre for Social and Economic Modelling's (NATSEM, University of Canberra) (http://www.natsem. canberra.edu.au) microsimulation model of Australia's income tax and transfer system. Typically, the model is used to assess distributional and individual impacts of income tax and welfare policies, and estimate impacts on the government's budget and distributional impacts of policy reform for families.

Using a dynamic microsimulation model, Australian Population and Policy Simulation Model (APPSIM), ${ }^{17}$ additional sociodemographic information was imputed onto the base population (age and sex profile in 2015, 2020, $2025,2030)$. APPSIM was developed by NATSEM in collaboration with 12 Australian Government departments, and simulates an annual snapshot of the Australian population from 2001 to 2051. Snapshots from 2015 to 2030 are used in this study.

The output data sets from Health\&WealthMOD2030 are the projected representation of the Australian population in 2015, 2020, 2025 and 2030. Demographic, socioeconomic, disease prevalence changes in the Australian population between the base years (ie, survey years 2003, 2009) and the projection years (ie, 2015, 2020, 2025, 2030) were captured through static ageing techniques. Both SDAC 2003 and 2009 data sets had survey weights assigned to each record by the ABS to account for unequal probability of individual selection in the surveys, and to make the survey data a true representation of the Australian population in the survey 


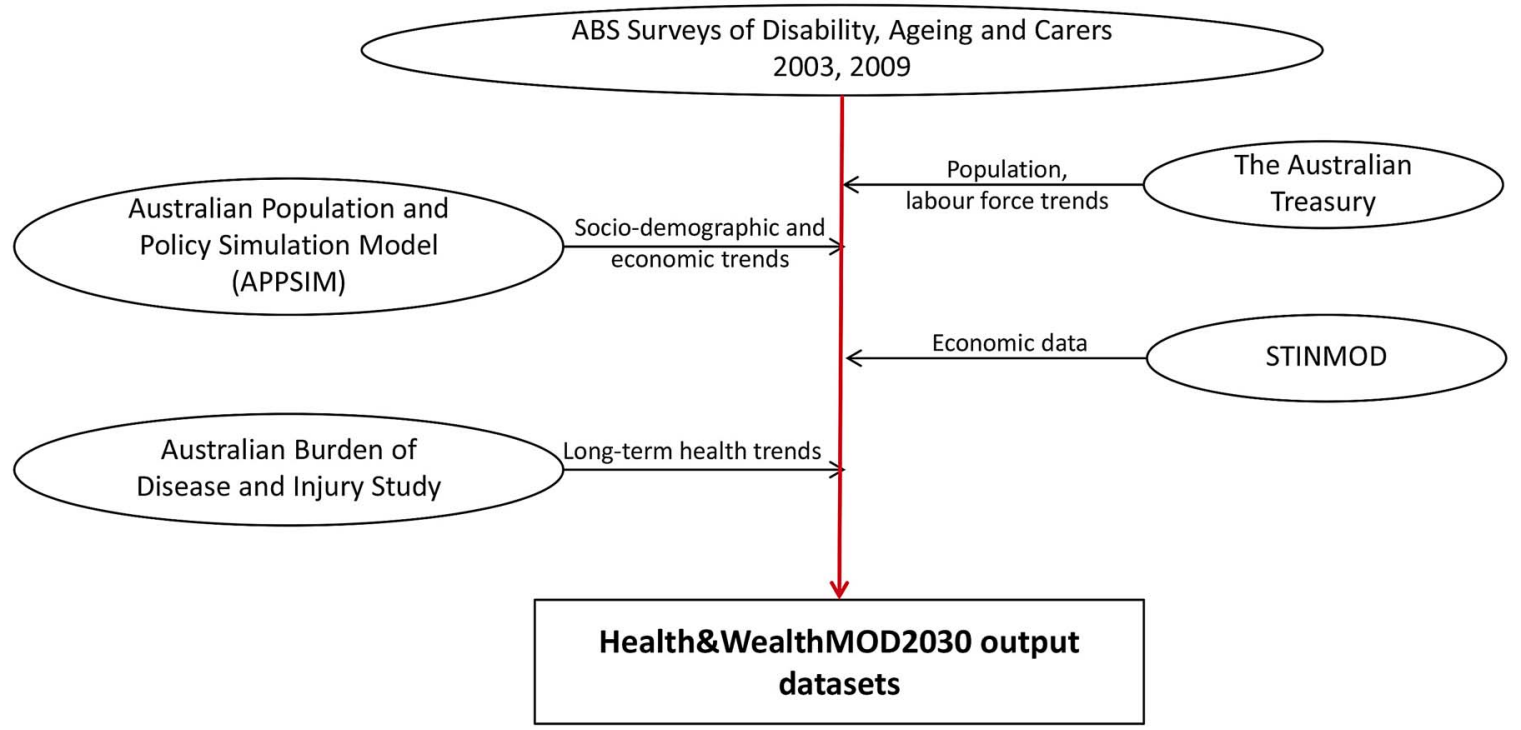

Figure 1 Schematic diagram of Health\&WealthMOD2030. ABS, Australian Bureau of Statistics; STINMOD, Static Incomes Model.

years. These weights reflect the number of people with similar characteristics in the Australian population in the year of surveys (2003 and 2009). SDAC 2003 and 2009 were separately reweighted using the ABS reweighting algorithm Generalised Regression Weighting Tool (GREGWT) to account for demographic, socioeconomic, disease prevalence changes in the population between the survey years $(2003,2009)$ and projection years $(2015,2020,2025,2030)$. GREGWT uses the generalised regression method to modify the initial survey weights (ie, 2003 and 2009 weights) such that the data sets with new weights become the representation of the Australian population for the projection years. The Commonwealth Treasury's 2013-2014 demographic and labour force projections were used to account for demographic and labour force changes over time. Chronic disease trends from the Australian burden of disease and injury study were used to account for changes in disease prevalence over time. ${ }^{18}$

To account for chronic condition trends, we applied the same trends in chronic condition incidence used in the 2003 Australian Burden of Disease and Injury Study. ${ }^{18}$ This study applied chronic disease trends from 2003 until 2023, after which time rates were assumed to stabilise. We calculated age-sex-specific proportional changes in chronic condition prevalence and applied these to corresponding diseases in SDAC data, aggregated into the following categories: stroke, cancer (almost stable in men and women), ischaemic heart disease (decreasing trend in men and women), type 2 diabetes (increasing trend in men and women) and chronic obstructive pulmonary disease (stable trend in men; increasing trend in women). In the absence of data on trends, the rates for all other conditions were assumed to remain stable. Based on proportional changes, the prevalence of chronic conditions among
Australians aged 45-64 years was projected for 2015 and 2030 by 5 -year age group and sex.

Economic data from STINMOD for 2013 were imputed onto Health\&WealthMOD2030 using synthetic matching. ${ }^{19}$ The matching process was described in detail in Schofield et al. ${ }^{15}$ Briefly, unit records of the STINMOD output for 2013 and the unit records of the Health\&WealthMOD2030 base population were matched on a set of matching variables common to both data sets and significantly related to income and the combined data set with variables from both STINMOD and Health\&WealthMOD2003 was synthetically created. Ten matching variables were used for synthetic matching. They were labour force status, income unit type, income quintile, receipt of aged pension, receipt of disability support pensions, sex, age group, hours of work per week, education and home ownership.

Finally, economic data from STINMOD 2013 were indexed to reflect economic growth projections from 2013 to 2030. Income and taxes paid by individuals were assumed to grow at a rate of $1 \%$ per annum (in real terms). ${ }^{20}$ Welfare payments were assumed to have no real growth based on the government's policy of increasing welfare payments (except for aged pension) in line with the national Consumer Price Index (CPI) growth. $^{21}$

The use of ABS SDAC 2003, 2009 data was approved by the ABS Microdata Review Panel.

\section{Lost PLYs due to chronic disease}

In the SDACs, respondents were asked to nominate their current labour force status as one of the following states:

1. Employed working full time

2. Employed working part-time

3. Unemployed looking for full-time work

4. Unemployed looking for part-time work

5. Not in the labour force 
Respondents who reported that they were not in the labour force were also asked to provide the main reason for not working or not looking for work. One of these options was 'own ill-health or disability'. All respondents were asked whether they had a long-term condition, and to nominate the type of condition they have from a list of 80 diseases. Those identified as (1) being out of the labour force due to their own ill health or disability and who (2) reported having a chronic condition were considered to have lost PLYs due to chronic disease in this study.

\section{Economic measures}

In this study, individual income refers to labour market earnings, income from other sources generating a return (such as rental properties, investments, interest on cash in bank) and welfare payments. Welfare payments in STINMOD relevant for older Australians include: aged pension, disability support pension, Newstart Allowance (for people looking for work), Carer Payment and Family Tax Benefit (http://www. humanservices.gov.au/customer/services).

Australian pensions are means tested payments not related to income earned prior to retirement. Thus, people with greater savings receive a smaller pension; for example, couples with assets (excluding their home) receive a reduced pension of $\$ A 440500$, and those with assets exceeding \$A1.17 million receive no pension (https://http://www.humanservices.gov.au/).

Taxes paid refer to income taxes paid (including Medicare levy) by individuals in a given timeframe (week, year).

\section{Statistical analysis}

Descriptive analysis was undertaken of associations between chronic disease and projected lost PLYs, income, taxes and welfare payments in 2015, 2020, 2025 and 2030. We present the mean (SD) and median weekly income, taxes paid and welfare payments of people aged 45-64 years out of the labour force because of ill health (lost PLYs) or in the labour force (employed full time with and without chronic disease, employed part-time with and without chronic disease). All figures are expressed in real 2013 Australian dollars.

A quantile regression model (adjusted for age, sex and highest level of education) of weekly income was used to estimate differences between the median weekly total income of people in employment and those with lost PLYs. This analysis was repeated for weekly taxes paid and welfare payments received.

The national impacts of lost PLYs due to chronic disease were estimated for 2015, 2020, 2025 and 2030 based on the assumption that if those not in the labour force because of ill health did not have the disease, all would be in the labour force, while some would work full time and some would work part-time. The probabilities of working full time and part-time were based on the estimated probabilities of working full time and parttime of those who did not have the disease and were in the labour force. The national impacts were estimated as the monetary value (cost in real 2013 Australian dollars) of the aggregate of lost income, extra welfare payments and lost taxation revenue due to lost PLYs in each year. A total of $95 \%$ CIs were generated for each outcome using bootstrapping with 1000 replications for each year.

All analyses were undertaken using SAS V.9.4 (SAS Institute, Cary, North Carolina, USA). All statistical tests were two sided with a significance level of $5 \%$.

\section{RESULTS}

Among the 19277 people aged 45-64 years with information on their labour force status in the combined SDACs, 6606 were employed full time with no chronic disease; 6076 were employed full time with a chronic disease; 2373 were employed part-time with no chronic disease; 2812 were employed part-time with a chronic disease; and 1410 were not in the labour force due to chronic disease, that is, lost PLYs in 2015. Once weighted, these data represent an Australian population aged 45-64 years of 4817000 people in 2015. Of these, $1651000(27.8 \%)$ were employed full time with no chronic disease; 1568000 (26.4\%) were employed full time with chronic disease; $525000(8.8 \%)$ were employed part-time with no chronic disease; $693000(11.7 \%)$ were employed part-time with chronic disease; and 380000 (6.4\%) had lost PLYs due to chronic condition in the Australian population aged $45-64$ years in 2015 . The remaining $19 \%$ correspond to people aged 45-64 years who are unemployed or not in the labour force due to reasons other than ill health (table 1).

People not in the labour force due to chronic disease received \$A391.61 in median weekly income and \$A321.87 in median weekly welfare payments (median income taxes paid was effectively $\$ \mathrm{~A} 0$ by definition of PLYs) in 2015 (table 1). People in this group obtained a significantly higher amount of welfare income per week than those employed full time or part-time, and the median weekly income taxes paid were significantly lower than that paid by people employed full time or part-time (table 1).

By 2030, the number of people aged 45-64 years was projected to be 6017000 , with 2019000 (28.3\%) employed full time with no chronic disease; 1960000 (27.5\%) employed full time with chronic disease; $677000(9.5 \%)$ employed part-time with no chronic disease; $899000 \quad(12.6 \%)$ employed part-time with chronic disease; and $462000(6.5 \%)$ who had lost PLYs due to chronic disease in the Australian population aged 45-64 years. Trends in labour status including not in the labour force because of ill health by age group over the period of 15 years from 2015 to 2030 is shown in table 2. People with lost PLYs due to chronic disease in 2030 were projected to receive $\$$ A393.15 a week in median income, $\$$ A311.67 a week in median welfare payments and pay effectively \$A0 in income taxes in 2030, expressed in real 2013 dollars (table 1). 


\begin{tabular}{|c|c|c|c|c|c|c|c|c|c|c|c|c|c|c|c|c|c|}
\hline \multirow[b]{2}{*}{ Labour force status } & \multirow[b]{2}{*}{$\begin{array}{l}\text { Number of } \\
\text { survey } \\
\text { records }\end{array}$} & \multicolumn{4}{|l|}{2015} & \multicolumn{4}{|l|}{2020} & \multicolumn{4}{|l|}{2025} & \multicolumn{4}{|l|}{2030} \\
\hline & & $\begin{array}{l}\text { population } \\
\text { (\%) }\end{array}$ & Mean & SD & Median & $\begin{array}{l}\text { Weighted } \\
\text { population }\end{array}$ & Mean & SD & Median & $\begin{array}{l}\text { Weighted } \\
\text { population }\end{array}$ & Mean & SD & Median & $\begin{array}{l}\text { Weighted } \\
\text { population }\end{array}$ & Mean & SD & Median \\
\hline \multicolumn{18}{|c|}{ Weekly total income $(\$ A)$ of individuals } \\
\hline $\begin{array}{l}\text { Employed full time with no } \\
\text { chronic condition }\end{array}$ & 6606 & $\begin{array}{l}1651000 \\
(27.77)\end{array}$ & 1626.93 & 1443.74 & 1344.76 & $\begin{array}{l}1784000 \\
(27.98)\end{array}$ & 1757.07 & 1554.70 & 1458.75 & $\begin{array}{l}1867000 \\
(27.96)\end{array}$ & 1901.26 & 1693.29 & 1567.26 & $\begin{array}{l}2019000 \\
(28.31)\end{array}$ & 2039.13 & 1832.26 & 1653.38 \\
\hline $\begin{array}{l}\text { Employed full time with a } \\
\text { chronic condition }\end{array}$ & 6076 & $\begin{array}{l}1568000 \\
(26.37)\end{array}$ & 1520.90 & 1600.42 & 1255.03 & $\begin{array}{l}1725000 \\
(27.06)\end{array}$ & 1636.20 & 1716.33 & 1351.01 & $\begin{array}{l}1827000 \\
(27.36)\end{array}$ & 1782.21 & 1873.76 & 1443.73 & $\begin{array}{l}1960000 \\
(27.49)\end{array}$ & 1916.72 & 2005.36 & 1529.27 \\
\hline $\begin{array}{l}\text { Employed part-time with no } \\
\text { chronic condition }\end{array}$ & 2373 & $\begin{array}{l}525000 \\
(8.84)\end{array}$ & 739.92 & 813.51 & 626.28 & $\begin{array}{l}583000 \\
(9.15)\end{array}$ & 792.30 & 881.92 & 666.83 & $\begin{array}{l}621000 \\
(9.30)\end{array}$ & 865.00 & 923.33 & 725.60 & $\begin{array}{l}677000 \\
(9.50)\end{array}$ & 931.39 & 948.32 & 783.39 \\
\hline $\begin{array}{l}\text { Employed part-time with a } \\
\text { chronic condition }\end{array}$ & 2812 & $\begin{array}{l}693000 \\
(11.65)\end{array}$ & 675.10 & 721.82 & 569.32 & $\begin{array}{l}780000 \\
(12.24)\end{array}$ & 723.32 & 769.64 & 601.25 & $\begin{array}{l}836000 \\
(12.52)\end{array}$ & 811.33 & 811.94 & 680.44 & $\begin{array}{l}899000 \\
(12.61)\end{array}$ & 892.99 & 847.83 & 741.10 \\
\hline $\begin{array}{l}\text { Not in labour force due to } \\
\text { chronic condition }\end{array}$ & 1410 & $\begin{array}{l}380000 \\
(6.39)\end{array}$ & 337.23 & 222.95 & 391.61 & $\begin{array}{l}415000 \\
(6.51)\end{array}$ & 343.36 & 246.50 & 393.15 & $\begin{array}{l}437000 \\
(6.54)\end{array}$ & 349.87 & 274.40 & 393.15 & $\begin{array}{l}462000 \\
(6.47)\end{array}$ & 357.45 & 297.91 & 393.15 \\
\hline \multicolumn{18}{|c|}{ Weekly welfare income $(\$ A)$ received by individuals } \\
\hline $\begin{array}{l}\text { Employed full time with no } \\
\text { chronic condition }\end{array}$ & 6606 & $\begin{array}{l}1651000 \\
(27.77)\end{array}$ & 19.54 & 64.44 & 0.00 & $\begin{array}{l}1784000 \\
(27.98)\end{array}$ & 18.70 & 63.04 & 0.00 & $\begin{array}{l}1867000 \\
(27.96)\end{array}$ & 16.55 & 59.24 & 0.00 & $\begin{array}{l}2019000 \\
(28.31)\end{array}$ & 15.57 & 57.80 & 0.00 \\
\hline $\begin{array}{l}\text { Employed full time with a } \\
\text { chronic condition }\end{array}$ & 6076 & $\begin{array}{l}1568000 \\
(26.37)\end{array}$ & 17.26 & 61.92 & 0.00 & $\begin{array}{l}1725000 \\
(27.06)\end{array}$ & 17.16 & 62.51 & 0.00 & $\begin{array}{l}1827000 \\
(27.36)\end{array}$ & 15.71 & 60.20 & 0.00 & $\begin{array}{l}1960000 \\
(27.49)\end{array}$ & 14.98 & 58.92 & 0.00 \\
\hline $\begin{array}{l}\text { Employed part-time with no } \\
\text { chronic condition }\end{array}$ & 2373 & $\begin{array}{l}525000 \\
(8.84)\end{array}$ & 64.49 & 129.45 & 0.00 & $\begin{array}{l}583000 \\
(9.15)\end{array}$ & 63.84 & 129.88 & 0.00 & $\begin{array}{l}621000 \\
(9.30)\end{array}$ & 59.83 & 125.96 & 0.00 & $\begin{array}{l}677000 \\
(9.50)\end{array}$ & 57.47 & 122.54 & 0.00 \\
\hline $\begin{array}{l}\text { Employed part-time with a } \\
\text { chronic condition }\end{array}$ & 2812 & $\begin{array}{l}693000 \\
(11.65)\end{array}$ & 87.37 & 154.05 & 0.00 & $\begin{array}{l}780000 \\
(12.24)\end{array}$ & 86.11 & 154.05 & 0.00 & $\begin{array}{l}836000 \\
(12.52)\end{array}$ & 78.01 & 147.33 & 0.00 & $\begin{array}{l}899000 \\
(12.61)\end{array}$ & 72.92 & 142.32 & 0.00 \\
\hline $\begin{array}{l}\text { Not in labour force due to } \\
\text { chronic condition }\end{array}$ & 1410 & $\begin{array}{l}380000 \\
(6.39)\end{array}$ & 295.02 & 172.98 & 321.87 & $\begin{array}{l}415000 \\
(6.51)\end{array}$ & 293.74 & 173.97 & 315.95 & $\begin{array}{l}437000 \\
(6.54)\end{array}$ & 289.36 & 176.73 & 311.67 & $\begin{array}{l}462000 \\
(6.47)\end{array}$ & 287.28 & 178.56 & 311.67 \\
\hline \multicolumn{18}{|c|}{ Weekly tax paid (includes Medicare levy) $(\$ A)$ by individuals } \\
\hline $\begin{array}{l}\text { Employed full time with no } \\
\text { chronic condition }\end{array}$ & 6606 & $\begin{array}{l}1651000 \\
(27.77)\end{array}$ & 364.23 & 475.20 & 253.49 & $\begin{array}{l}1784000 \\
(27.98)\end{array}$ & 398.29 & 516.12 & 281.34 & $\begin{array}{l}1867000 \\
(27.96)\end{array}$ & 434.57 & 560.89 & 302.60 & $\begin{array}{l}2019000 \\
(28.31)\end{array}$ & 469.49 & 610.95 & 320.21 \\
\hline $\begin{array}{l}\text { Employed full time with a } \\
\text { chronic condition }\end{array}$ & 6076 & $\begin{array}{l}1568000 \\
(26.37)\end{array}$ & 327.73 & 480.01 & 215.29 & $\begin{array}{l}1725000 \\
(27.06)\end{array}$ & 356.01 & 520.54 & 236.90 & $\begin{array}{l}1827000 \\
(27.36)\end{array}$ & 390.38 & 565.75 & 259.61 & $\begin{array}{l}1960000 \\
(27.49)\end{array}$ & 422.33 & 609.79 & 280.54 \\
\hline $\begin{array}{l}\text { Employed part-time with no } \\
\text { chronic condition }\end{array}$ & 2373 & $\begin{array}{l}525000 \\
(8.84)\end{array}$ & 92.94 & 225.74 & 26.23 & $\begin{array}{l}583000 \\
(9.15)\end{array}$ & 102.53 & 244.36 & 29.07 & $\begin{array}{l}621000 \\
(9.30)\end{array}$ & 111.89 & 251.43 & 36.67 & $\begin{array}{l}677000 \\
(9.50)\end{array}$ & 118.82 & 254.15 & 45.33 \\
\hline $\begin{array}{l}\text { Employed part-time with a } \\
\text { chronic condition }\end{array}$ & 2812 & $\begin{array}{l}693000 \\
(11.65)\end{array}$ & 68.43 & 164.48 & 5.42 & $\begin{array}{l}780000 \\
(12.24)\end{array}$ & 76.13 & 179.30 & 6.51 & $\begin{array}{l}836000 \\
(12.52)\end{array}$ & 88.79 & 192.11 & 21.07 & $\begin{array}{l}899000 \\
(12.61)\end{array}$ & 99.67 & 204.00 & 28.78 \\
\hline $\begin{array}{l}\text { Not in labour force due to } \\
\text { chronic condition }\end{array}$ & 1410 & $\begin{array}{l}380000 \\
(6.39)\end{array}$ & 2.00 & 50.11 & 0.00 & $\begin{array}{l}415000 \\
(6.51)\end{array}$ & 2.72 & 60.42 & 0.00 & $\begin{array}{l}437000 \\
(6.54)\end{array}$ & 3.51 & 71.38 & 0.00 & $\begin{array}{l}462000 \\
(6.47)\end{array}$ & 4.17 & 80.06 & 0.00 \\
\hline
\end{tabular}




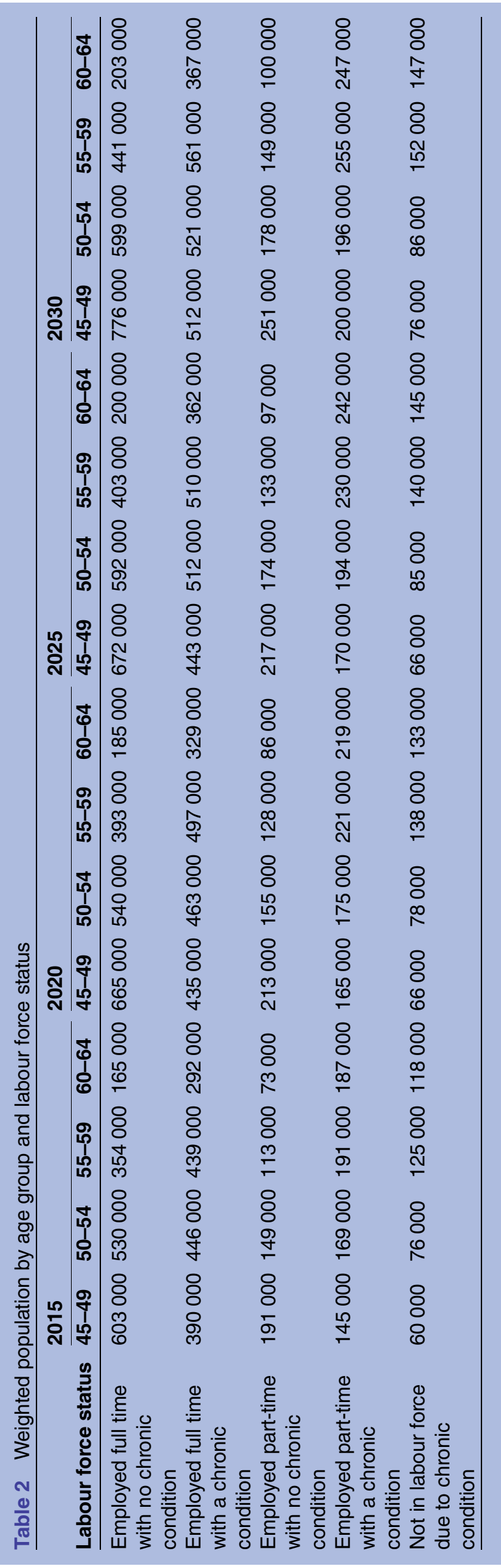

After adjusting for age, sex and education, it was estimated that in 2015, those out of the labour force due to ill health obtained \$A805.32 per week $(95 \%$ CI \$A769.11 to \$A837.17) less in median income than those employed full time with no chronic disease in 2015 (table 3). Median weekly welfare payments were significantly higher with this group receiving \$A321.88 per week (95\% CI $\$ A 311.67$ to $\$ A 344.43)$ more in (median) welfare payments than those employed full time with no chronic disease (with employed people receiving a median weekly welfare income of $\$ \mathrm{~A} 0$ ) (table 3). People out of the labour force due to chronic disease also paid \$A203.13 per week (95\% CI \$A194.01 to $\$$ A217.40) less in income taxes than those employed full time without chronic disease.

Differences in median weekly income, welfare payments and income taxes between people in the different labour force/health status groups were estimated for 2030 (table 3, last two columns). Income lost as a result of being out of the labour force due to chronic disease increased from \$A805.32 per week in 2015 (95\% CI $\$ \mathrm{~A} 769.11$ to $\$ \mathrm{~A} 837.17)$ to $\$ \mathrm{~A} 1057.73$ per week in 2030 (95\% CI $\$ \mathrm{~A} 1011.64$ to $\$ \mathrm{~A} 1091.49)$ in real terms (compared to those employed full time with no chronic disease). People with lost PLYs due to chronic disease paid $\$$ A203.13 per week (95\% CI $\$$ A194.01 to $\$$ A217.40) less in income taxes than those employed full time without chronic disease in 2015 , increasing to $\$$ A257.73 per week (95\% CI \$A242.58 to \$A272.45) in 2030.

The national impacts of lost PLYs due to chronic disease in older workers from 2015 to 2030 are presented in table 4. Lost annual income was $\$$ A12.6 billion due to lost PLYs in 2015, increasing to $\$$ A20.5 billion in 2030 (ie, a $62.7 \%$ absolute increase) mainly due to population growth and ageing. Additional welfare payments due to lost PLYs were also projected to increase, from $\$$ A6.2 billion in 2015 to $\$$ A7.3 billion in 2030 (a $17.7 \%$ absolute increase). Finally, lost annual tax revenue due to lost PLYs was projected to increase in real terms over time, from $\$$ A3.1 billion in 2015 to $\$$ A 4.7 billion in 2030 (absolute growth of 51.6\%).

\section{DISCUSSION}

This study projected lost PLYs due to chronic disease in older workers (aged 45-64 years) and the significant flow-on effects for individuals (lost income) and government (lost taxes, extra welfare payments) from 2015 to 2030 - the first set of results of its kind for Australia. We projected lost personal income due to lost PLYs to increase from $\$$ A12.6 billion in 2015 to $\$$ A20.5 billion in 2030 (a $62.70 \%$ absolute increase). We also projected lost taxation revenue due to lost PLYs to increase from \$A3.1 billion in 2015 to \$A4.7 billion in 2030 (an absolute increase of $51.6 \%$ ), which will put greater pressure on government budgets. Greater reliance on public healthcare is expected by those who retire early due to ill health, and increasing costs are likely to occur 
秀余

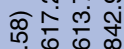

○ 1

옹ㅇㅇㅇ

ति

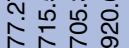

IIII

ก 융ㅁㄴ 는

จำ

웅웅웅웅

f于

क⿺辶

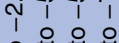

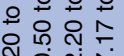

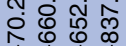

IIII

)

ริ

$\varangle$ 잉

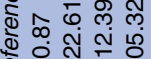

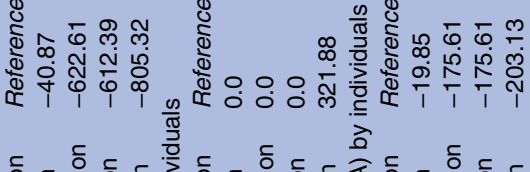

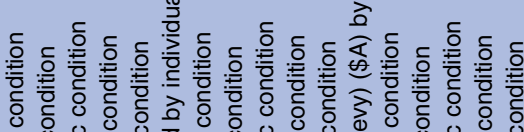

흥
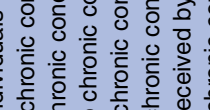

응 은

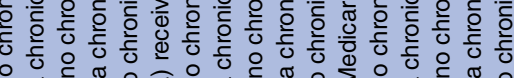

โ
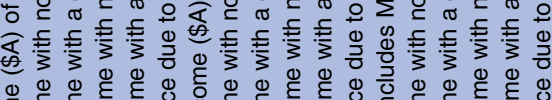

光

because more people will be eligible for age/disability pensions in the future. ${ }^{22}$

According to the WHO, chronic diseases are one of the foremost health and development challenges facing countries in the 21st century, through both the human suffering they cause and the reduced social and economic well-being of citizens. ${ }^{23}{ }^{24}$ In the absence of evidence-based actions, the human, social and economic costs of chronic diseases will continue to grow and overwhelm the capacity of countries to address them. For these reasons, local and international research projecting the economic costs of chronic diseases is growing. These studies commonly emphasise the need for better organisation, adequate funding to improve the availability of diagnosis and treatment of chronic diseases, as well as health promotion and early prevention. Recently, the authors of a report for the American Heart Association, Forecasting the future of cardiovascular disease in the United States, ${ }^{25}$ projected the direct and indirect costs associated with a projected $40.5 \%$ of the US population having some form of cardiovascular disease by 2030 . The total direct (healthcare) costs of cardiovascular disease are projected to triple, from $\$ A 273$ billion in 2010 to $\$$ A818 billion in 2030. Real indirect costs (due to lost productivity) for all forms of cardiovascular disease are estimated to increase from $\$$ A172 billion in 2010 to $\$ A 276$ billion in 2030 (a $61 \%$ increase). The report's authors emphasise that heart and vascular diseases can be effectively prevented, and the main strategy to combat the epidemic of cardiovascular disease in the USA should be a reorientation of the health system in the direction of effective health promotion and prevention. However, few studies have estimated the economic impacts of chronic diseases specifically for older workers in OECD and WHO countries. Harbers and Achterberg ${ }^{10}$ estimated the burden of five chronic diseases in individuals of pre-retirement and postretirement age ( 50 years), the number of people exiting the labour market because of chronic disease (unemployment, early retirement), and the health impacts of exiting for individuals in the OECD in the late 2000s. Abegunde and Stanciole's ${ }^{11}$ approach differs from that in the OECD report in that they projected the costs of deaths from three chronic diseases (heart disease, stroke, diabetes) measured by lost income and lost GDP (ie, national, societal costs) from 2005 to $2015 .^{11}$ This study makes a further advancement by projecting the costs of older workers exiting the labour market due to chronic disease (lost PLYs) for individuals, government and the nation as a whole using a microsimulation model integrating output from long-standing models and reliable data. There is a potential application of PLYs lost and the economic costs associated with it in cost-benefit models and Disability Adjusted Life Years estimates in intervention studies.

There is an ongoing debate about how health and income are related. Weil ${ }^{26}$ maintains that there are reliable reasons for accepting the causality between these 
Table 4 National annual economic impacts of lost labour force participation caused by chronic disease (million $\$ \mathrm{~A}$ )

\begin{tabular}{|c|c|c|c|c|c|c|c|c|}
\hline \multirow[b]{2}{*}{ Cost } & \multicolumn{2}{|l|}{2015} & \multicolumn{2}{|l|}{2020} & \multicolumn{2}{|l|}{2025} & \multicolumn{2}{|l|}{2030} \\
\hline & $\begin{array}{l}\text { \$A } \\
\text { impact }\end{array}$ & $95 \% \mathrm{Cl}$ & $\begin{array}{l}\text { \$A } \\
\text { impact }\end{array}$ & $95 \% \mathrm{Cl}$ & $\begin{array}{l}\text { \$A } \\
\text { impact }\end{array}$ & $95 \% \mathrm{Cl}$ & $\begin{array}{l}\text { \$A } \\
\text { impact }\end{array}$ & $95 \% \mathrm{Cl}$ \\
\hline Lost income & 12593 & (11 560 to 13630 ) & 15277 & (13 880 to 16428 ) & 17661 & (16 113 to 19136$)$ & 20514 & (18 838 to 22001 ) \\
\hline $\begin{array}{l}\text { Extra welfare } \\
\text { payments }\end{array}$ & 6188 & (5719 to 6780 ) & 6668 & (6248 to 7406$)$ & 6924 & (6542 to 7604$)$ & 7321 & (6958 to 7987 ) \\
\hline $\begin{array}{l}\text { Lost tax } \\
\text { revenue }\end{array}$ & 3090 & (2850 to 3398 ) & 3617 & (3281 to 3993) & 4166 & (3771 to 4545 ) & 4663 & (4231 to 5096 ) \\
\hline
\end{tabular}

two variables to run in both directions. Individuals in better health are more productive, learn more in formal educational settings and have more incentives to accrue human capital because they live longer. Likewise, higher income for individuals (or countries) improves health in a range of ways, from improved nutrition to building public health infrastructure including investment in the health professionals' workforce. There is empirical evidence that both of these causal channels are operational; however, the magnitude of the effects is limited when applied to cross-sectional differences among individuals or countries. There is evidence that 'other factors' that concurrently increase income and improve health outcomes (such as human capital for individuals, and institutional quality for countries) account for a significant amount of the observed correlation between health and income. ${ }^{26}$ We have attempted to account for some of these 'other factors' in our models by including demographic (age, sex) and human capital (education -highest level of educational achievement) variables.

In Australia, the assertion that increased longevity automatically translates into longer years in good health during later working life is not supported by our research, ${ }^{2}$ which suggests that despite increases in longevity there is no improvement in the health status of the older workers. Furthermore, the Productivity Commission's ${ }^{27}$ report An ageing Australia raised the prospect of increased longevity without increased years of healthy life, highlighting credible evidence that over time there has been an expansion of, rather than a compression in, morbidity in Australia. ${ }^{27}$ The report also cited the example of adverse impacts of lifestyle factors (including growing obesity) on longevity leading to an increased prevalence of diseases such as diabetes. ${ }^{27}$ Thus, there are conflicting views about the impact of income growth and chronic disease prevalence versus views that the reverse is happening in Australia.

This study has some limitations. Findings are based on SDAC respondents' self-reported labour force status and chronic disease. Although self-reported employment status and health are regarded as valid measures for such studies, ${ }^{28}{ }^{29}$ there is the potential for bias in results. Although the SDACs are cross-sectional data, some survey questions were designed in a way to capture causal relationships. For example, the SDACs have 'own ill-health or disability' as a category for the main reason respondents are out of the labour force (causal relationship).

Although several policies have been implemented to encourage older workers to remain in the labour force longer in the OECD, ${ }^{6}$ those based on financial incentives may not be sufficient to increase participation because ill health is commonly the stated reason for exiting. Greater investment in preventive health interventions that improve older workers' health and capacity to work is needed to maintain labour force participation, economic growth and to ensure that future governments have sufficient revenue for funding the healthcare of an ageing population. ${ }^{22} 30$ The timely management of pain due to back problems, for example, has been shown to reduce the detrimental impacts of this condition on individuals, including labour force participation and related costs such as reduced wealth. ${ }^{31}$ Preventative or treatment practices for back problems shown to be effective in randomised controlled trials (such as physical exercise ${ }^{32}$ and continued daily activity ${ }^{33}$ ) should continue to be encouraged in order to prevent the onset of back problems or reduce their severity (and resultant pain) in sufferers, as well as the substantial costs of lost labour force participation caused by such problems for individuals and the government.

\section{Author affiliations}

${ }^{1}$ Faculty of Pharmacy, Charles Perkins Centre, The University of Sydney, Sydney, New South Wales, Australia

2Murdoch Children's Research Institute, Royal Children's Hospital Flemington Road, Parkville, Victoria, Australia

${ }^{3}$ Garvan Institute of Medical Research, Victoria Street, Darlinghurst, Sydney, New South Wales, Australia

${ }^{4}$ National Centre for Social and Economic Modelling, University of Canberra, Canberra, Australian Capital Territory, Australia

${ }^{5}$ Faculty of Medicine and Biomedical Sciences, School of Public Health, University of Queensland, Brisbane, Queensland, Australia

${ }^{6}$ University Centre for Rural Health, School of Public Health, The University of Sydney, Lismore, New South Wales, Australia

Funding The development of the microsimulation model used in this research, Health\&WealthMOD2030, was funded by the Australian Research Council (under grant LP100100158), and Pfizer Australia was a partner to the grant. MP was funded by fellowships from the National Health and Medical Research Council, the NSW Cancer Institute and the Sydney Medical School Foundation. All authors are independent from the funding sources, and the funding sources (including Pfizer Australia) played no part in the research design, undertaking of the analysis, formulation or interpretation of the results, decision to publish the research findings, nor in any other part of the research process. 
Contributors DS conceived and led the study. RNS, SJK, RT and LV developed the models. RNS and MMC analysed the data. MMC wrote the initial draft of the paper. RNS developed Health\&WealthMOD2030. SJK developed APPSIM. LV worked on the health trend data. RT worked on STINMOD and weighting the data. MEP and LV provided expert opinion on disease prevalence and trends.

\section{Funding Australian Research Council (LP100100158).}

Competing interests None declared.

Provenance and peer review Not commissioned; externally peer reviewed.

Data sharing statement The data used in this study are from Health\&WealthMOD2030, a microsimulation model constructed by the authors from the Survey of Disability, Ageing and Carers (SDACs) 2003 and 2009, STINMOD, APPSIM, population and labour force growth data from Treasury and disease trends data from the 2003 Australian Burden of Disease and Injury Study. The SDACs 2003 and 2009 are publicly available through the Australian Bureau of Statistics. Enquiries regarding access to other data sets and Health\&WealthMOD2030 should be directed to Professor Deborah Schofield, deborah.schofield@sydney.edu.au.

Open Access This is an Open Access article distributed in accordance with the Creative Commons Attribution Non Commercial (CC BY-NC 4.0) license, which permits others to distribute, remix, adapt, build upon this work noncommercially, and license their derivative works on different terms, provided the original work is properly cited and the use is non-commercial. See: http:// creativecommons.org/licenses/by-nc/4.0/

\section{REFERENCES}

1. Global Burden of Disease Study 2013 Collaborators. Global, regional, and national incidence, prevalence, and years lived with disability for 301 acute and chronic diseases and injuries in 188 countries, 1990-2013: a systematic analysis for the Global Burden of Disease Study 2013. Lancet 2015;386:743-800.

2. Schofield DJ, Shrestha RN, Cunich M, et al. Lost productive life years caused by chronic conditions in Australians aged 45-64 years, 2010-2030. Med J Aust 2015;203:260.e1-6.

3. Organisation for Economic Co-operation and Development. Sickness, disability and work: breaking the barriers. Paris: OECD Publishing, 2007

4. Organisation for Economic Co-operation and Development Media Relations. OECD says governments must help people with reduced work capacity get jobs (18 December 2007). Paris: OECD, 2007.

5. Australian Bureau of Statistics. Retirement and retirement intentions, Australia, July 2012 to June 2013 (cat. no. 6238.0). Canberra: Australian Bureau of Statistics, 2013

6. Cooke M. Policy changes and the labour force participation of older workers: evidence from six countries. Can J Aging 2006;25:387-400.

7. Department of Employment. Restart Wage Subsidy. Secondary Restart Wage Subsidy 2014. http://www.employment.gov.au/ restart-wage-subsidy

8. Access Economics. The economic cost of arthritis in New Zealand, Report for Arthritis New Zealand, Canberra, June 2005.

9. Doran CM. The evidence on the costs and impacts on the economy and productivity due to mental ill health: an evidence check rapid review brokered by the Sax Institute (http://www.saxinstitute.org.au) for the mental health commission of NSW. Sydney: Sax Institute, 2013.

10. Harbers MM, Achterberg PW. Europeans of retirement age: chronic diseases and economic activity. Bilthoven: RIVM, 2012.

11. Abegunde D, Stanciole A. An estimation of the economic impact of chronic noncommunicable diseases in selected countries (working paper). Geneva: World Health Organization, Department of Chronic Diseases and Health Promotion (CHP), 2006.

12. Schofield DJ, Shrestha RN, Percival R, et al. The personal and national costs of early retirement because of spinal disorders: impacts on income, taxes, and government support payments. Spine J 2012;12:1111-18.

13. Australian Bureau of Statistics. Information Paper-Basic Confidentialised Unit Record File: Survey of Disability, Ageing and Carers 2003 (reissue). Canberra: Australian Bureau of Statistics, 2005.

14. Australian Bureau of Statistics. Survey of Disability, Ageing and Carers 2009 Cat. No. 4430.0. Canberra: Australian Bureau of Statistics, 2012

15. Schofield D, Shrestha R, Kelly S, et al. Health\&WealthMOD2030: a microsimulation model of the long term economic impacts of disease on the labour force participation of Australians aged 45-64 years old. Int J Microsimul 2014;7:94-118.

16. Lambert S, Warren N. STINMOD—STATAX: A Comprehensive Model of the Incidence of Taxes and Transfers in Australia. NATSEM Technical Paper. March 1999.

17. Keegan M, Kelly S. APPSIM-dynamic microsimulation modelling of social security and taxation. Canberra: National Centre for Social and Economic Modelling, University of Canberra, 2009.

18. Begg S, Vos T, Barker B, et al. The burden of disease and injury in Australia 2003. Canberra: Australian Institute of Health and Welfare, May 2007.

19. Rässler S. Statistical matching: a frequentist theory, practical applications, and alternative Bayesian approaches. New York: Springer-Verlag New York, Inc., 2002.

20. Treasury. Budget Paper No 1: Budget Strategy and Outlook 2015-16. Canberra: Commonwealth Treasury, 2015.

21. Department of Human Services. A guide to Australian government payments. Canberra: Australian Government, 2015.

22. Commonwealth of Australia. 2015 intergenerational report: Australia in 2055. Canberra: The Commonwealth of Australia, 2015.

23. Bloom DE, Cafiero ET, Jané-Llopis E, et al. The global economic burden of noncommunicable diseases. Geneva: World Economic Forum, 2011.

24. Jha P, Nugent R, Verguet S, et al. Third Copenhagen Consensus: Chronic Disease Assessment. Copenhagen: Copenhagen Consensus Center, 2012.

25. Heidenreich PA, Trogdon JG, Khavjou OA et al. Forecasting the future of cardiovascular disease in the United States: a policy statement from the American Heart Association. Circulation 2011;123:933-44.

26. Weil DN. Health and economic growth (chapter 3). In: Aghion P, Durlauf SN, eds. Handbook of economic growth. Vol. 2B. Boston: Elsevier, 2014:623-82.

27. Productivity Commission. An ageing Australia: preparing for the future. Productivity Commission Research Report. Canberra: Commonwealth of Australia, 2013.

28. Wannamethee G, Shaper AG. Self-assessment of health status and mortality in middle-aged British men. Int $J$ Epidemiol 1991;20:239-45.

29. Cai L, Kalb G. Health status and labour force participation: evidence from the HILDA data. Melbourne Institute of Applied Economic and Social Research, 2004.

30. Russell LM, Rubin GL, Leeder SR. Preventive health reform: what does it mean for public health? Med J Aust 2008;188:715-19.

31. Buchbinder R, Jolley D, Wyatt M. Breaking the back of back pain. Med J Aust 2001;175:456-7.

32. Driessen MT, Proper KI, van Tulder MW, et al. The effectiveness of physical and organisational ergonomic interventions on low back pain and neck pain: a systematic review. Occup Environ Med 2010;67:277-85.

33. Abenhaim L, Rossignol M, Valat JP, et al. The role of activity in the theraputic management of low back pain: Report of the International Paris Task Force on Back Pain. Spine (Phila Pa 1976) 2000;25(4 Suppl):1S-33S. 